\title{
Short communication: Characterization of Staphylococcus aureus from bulk tank milk of dairy cattle in Lombardy (northern Italy)
}

\author{
A. Gazzola,,${ }^{1,2} \odot$ A. M. Maisano,,${ }^{1 *}$ V. Bianchini, ${ }^{1}$ F. Vezzoli, ${ }^{1}$ A. Romanò,,${ }^{1,3}$ H. U. Graber, ${ }^{3} \odot$ P. Cremonesi, ${ }^{4} \odot$ \\ G. Zanardi, ${ }^{5}$ V. Cappa, ${ }^{6}$ and M. Luini ${ }^{1}$ (I) \\ ${ }^{1}$ Istituto Zooprofilattico Sperimentale della Lombardia e dell'Emilia-Romagna, 26900 Lodi, Italy \\ ${ }^{2}$ Infectious Diseases Unit, Fondazione IRCCS "San Matteo," 27100 Pavia, Italy \\ ${ }^{3}$ Agroscope, Food Microbial Systems, Group Microbiological Safety of Foods of Animal Origin, 3003 Berne, Switzerland \\ ${ }^{4}$ Institute of Agricultural Biology and Biotechnology, National Research Council, 26900 Lodi, Italy \\ ${ }^{5}$ Istituto Zooprofilattico Sperimentale della Lombardia e dell'Emilia-Romagna, Reparto Produzione Primaria, 25124 Brescia, Italy \\ ${ }^{6}$ Istituto Zooprofilattico Sperimentale della Lombardia e dell'Emilia-Romagna, Osservatorio Epidemiologico Veterinario Regione Lombardia, \\ 25124 Brescia, Italy
}

\begin{abstract}
Staphylococcus aureus is one of the most important pathogens causing mastitis in cattle, and it is responsible for economic losses in dairy herds worldwide. The PCR amplification of the 16S-23S rRNA intergenic spacer (ribosomal spacer PCR, RS-PCR) allows a rapid classification of the strains in genotypes and genotypic clusters (CL), which are characterized by different epidemiological and clinical properties. Both RS-PCR and multi-locus sequence typing (MLST) were performed on strains isolated from bovine bulk tank milk (BTM) collected from dairy herds located in the Lombardy region (northern Italy), to outline the distribution of Staph. aureus genotypes in this geographical area. Out of 844 examined samples, 398 were positive for Staph. aureus, with a variable count $(\mathrm{cfu} / \mathrm{mL})$. Up to 8 colonies from each sample were genotyped. A total of 1,101 Staph. aureus strains were analyzed with RS-PCR, and only a selection of them $(\mathrm{n}=86)$, in relation to their frequency and geographical origin, underwent MLST. This study revealed 8 major genotypic clusters (CLB, CLC, CLR, CLS, CLI, CLF, CLAO, and CLZ), of which Staph. aureus CLB (29.3\%) was the most common. Samples of BTM positive for CLB had a Staph. aureus $\mathrm{cfu} / \mathrm{mL}$ count significantly higher than the non-CLB positive ones. Our MLST analysis showed genotypes already known as bovine-associated in literature, such as clonal complexes CC8, CC97, and CC151. The same selection of 86 strains was also analyzed for the presence of the $a d l b$ gene, which was recently proposed as a possible marker of contagiousness. Most Staph. aureus
\end{abstract}

Received June 27, 2019.

Accepted November 17, 2019.

*Corresponding author: antoniomarco.maisano@izsler.it belonging to CLB or CC8 carried the adlb gene (85\%), whereas this gene was detected in only $9 \%$ of non-CLB strains (CLAA, CLBI, CLBJ, CLS). In conclusion, the present study confirms that Staph. aureus CLB, which is recognized as a contagious genotype, is a particularly relevant agent of intramammary infection in dairy cows in Lombardy, and indirectly supports the idea that adlb can be a possible marker of contagiousness of isolates. Key words: Staphylococcus aureus, bulk tank milk, genotyping, adlb gene

\section{Short Communication}

Staphylococcus aureus is one of the most important pathogens causing mastitis in cattle, affecting both milk production and quality, and leading to relevant losses for dairy farmers (Hogeveen et al., 2011). In several farms, Staph. aureus IMI are reported to be widespread, with up to 70 to $80 \%$ of cows infected and strong increases in SCC compared with other farms, in which the infection affects only a few animals without spreading within the herd (Luini et al., 2015; Cosandey et al., 2016); this behavior depends on the Staph. aureus strain (e.g., genotype) circulating in the herd and involved in the IMI (Graber et al., 2009).

For years, ribosomal spacer PCR (RS-PCR) has been used to classify the isolates in several genotypes that can be grouped in clusters (CL). Each CL includes the genotype itself and its variants, differing in only one band after the electrophoretic analysis (Syring et al., 2012; Cosandey et al., 2016). Previous studies carried out in Switzerland and Italy have demonstrated that Staph. aureus genotype B (GTB) is very contagious, and it is associated with high within-herd prevalence of IMI (Fournier et al., 2008; Cremonesi et al., 2015). Moreover, a European survey showed a great variety of Staph. aureus genotypes and observed the presence of 
GTB in most of the considered countries (Cosandey et al., 2016). However, some strains belonging to genotypes different from CLB (the cluster that includes GTB), such as CLR or CLS, are also reported to be associated with high within-herd prevalence of IMI (Cremonesi et al., 2015; unpublished data). Furthermore, Staph. aureus $\mathrm{CLB}$ are almost all enterotoxin-producing (types $\mathrm{A}, \mathrm{D}$, and $\mathrm{J}$ ) and can contaminate dairy products, such as the traditional dairy products of small-scale alpine farms, where CLB is very common (Hummerjohann et al., 2014; Filipello et al., 2019). In fact, ingestion of enterotoxins produced by Staph. aureus in food can result in staphylococcal food poisoning, and several outbreaks linked to consumption of raw milk cheese and artisanal cheese have been reported (Johler et al., 2015; Kümmel et al., 2016).

Somatic cell counts have generally been accepted and used as measures of severity of IMI and indicators of economic losses (Petzer et al., 2017). Although numerous factors can influence the SCC in individual cows and at udder-quarter level - such as parity, lactation stage, incorrect milking machine settings, stress, and more - the most important cause remains the infection status of the mammary gland (Petzer et al., 2017).

Recently, it has been demonstrated that the newly discovered single copy gene adlb, which codes for adhesion-like bovine protein, is strictly related to Staph. aureus GTB and may be a potential marker of contagiousness. This gene is part of the GTB-specific staphylococcal cassette chromosome, SCCgtb (Sartori et al., 2017).

The northern Italian region of Lombardy is home to more than 5,000 bovine herds and produces more than $40 \%$ of Italian milk. A previous study analyzed bulk tank milk (BTM) collected in this area and aimed at evaluating methicillin-resistant Staph. aureus (MRSA) presence in dairy herds: methicillin-sensitive Staph. aureus (MSSA) and MRSA were detected in $47.2 \%$ and $3.8 \%$ of dairy herds, respectively (Cortimiglia et al., 2016). Our study considered the same samples used in that investigation and aimed at evaluating the genetic variability of Staph. aureus circulating in Lombardy herds, by means of RS-PCR, multi-locus sequence typing (MLST), and the adlb gene. The relation between the Staph. aureus genotypes and the Staph. aureus count or the SCC in the corresponding BTM sample was also investigated.

The same sampling carried out for the study of Cortimiglia and coworkers (2016) was used for this study. The sampling criteria are described in that paper, from which a total of 844 BTM samples were collected between July 2012 and October 2013. The samples were collected from 844 herds among the 7,008 dairy herds located in the Lombardy region. In particular, the herds were randomly chosen according to the number of herds present in each of the 11 provinces of Lombardy.

After collection, milk samples were transported chilled to the laboratory and stored at $-20^{\circ} \mathrm{C}$ until analysis. Bacteriological analysis was performed with standard techniques, as previously described by Cortimiglia et al. (2016), for Staph. aureus counts and MRSA detection. After bacteriological analysis, sodium azide (0.024 $\mathrm{g} / 100 \mathrm{~mL}$ ) was added to the samples, and the analysis for determining SCC was performed within $48 \mathrm{~h}$ using a Fossomatic 5000 (Foss Analytics, Hillerød, Denmark). Moreover, 5 Staph. aureus isolates from each positive sample were genotyped via RS-PCR. In case of different cultural morphologies of the colonies, up to 8 isolates per sample were selected. For this analysis, Staph. aureus DNA was isolated using DNeasy Blood and Tissue kit (Qiagen, Hilden, Germany), whereas RS-PCR was carried out according to Fournier et al. (2008). The PCR products were analyzed using the miniaturized electrophoresis system DNA 7500 LabChip (Agilent Technologies, Santa Clara, CA; Fournier et al., 2008).

Finally, MLST (Enright et al., 2000) and adlb-targeted real-time PCR (Sartori et al., 2017) analyses were performed on a selected group of 86 strains (each one representing the isolates found in the corresponding BTM and belonging to given RS-PCR clusters), representing as much as possible those circulating in dairy cattle farms in the Lombardy region. Among these 86 strains, 54 were MSSA; they were selected from all the MSSA isolates found in the different samples, considering the geographical distribution of the herds of origin and including both the more prevalent RSPCR genotypic clusters and strains belonging to rare clusters. The remaining 32 MRSA strains were all the MRSA strains previously isolated and analyzed via MLST by Cortimiglia and coworkers (2016). Moreover, for MSSA and MRSA strains, the MLST results were depicted by constructing a minimum spanning tree with BioNumerics 7.6 (Applied Maths, Sint-MartensLatem, Belgium). Statistical analysis was carried out to evaluate the association between the Staph. aureus genotypes circulating in the herds and the Staph. aureus count or SCC in the corresponding BTM sample. The analysis considered only the BTM samples in which every Staph. aureus isolate belonged to the same genotypic CL, and only the CL with a frequency of at least 10 observations (i.e., herds) were considered, to ensure enough significance of the analysis. Staphylococcus aureus $\mathrm{cfu} / \mathrm{mL}$ counts and the SCC in BTM were evaluated considering the CL found in the same samples. To perform the analysis, Staph. aureus count and SCC were transformed in natural logarithm (log), 
and all records reporting counts equal to 0 were recorded as missing values (6 counts). Categorical data were summarized as counts and percentages, continuous variables were described with mean and standard deviation (SD), and counts were expressed into original unit of measurement. Boxplots were used to describe the distributions by genotypic CL. To evaluate whether CL and SCC influenced Staph. aureus count, a linear regression model was fitted considering Staph. aureus log-count as dependent variable and CL and log-count of SCC as independent; residuals of the model followed approximately a normal distribution, and normality assumptions were respected. Clusters were then associated with log-SCC; the logarithmic transformation (Ali and Shook, 1980) was preferred to the linear score proposed by Fetrow et al. (1988) for normality assumptions. A linear regression model was built considering log-SCC as dependent variable and CL as independent. All means and estimates of the statistical analysis were reported in the original unit of measurement. All analyses were performed assuming a significance level of $5 \%$, using the statistical software R, version 3.5.1 (R Foundation for Statistical Computing, Vienna, Austria).

Out of 844 BTM samples, 47.2\% [95\% confidence interval (CI): 43.8 to 50.5\%] gave positive results for Staph. aureus culture. The highest prevalence was observed in the herds located in the province of Sondrio $(68.5 \%)$, whereas the lowest was registered in the province of Como (29.2\%). Among Staph. aureus-positive samples, 175 had a count in the range of 10 to 100 $\mathrm{cfu} / \mathrm{mL}, 129$ between 101 and $800 \mathrm{cfu} / \mathrm{mL}$, and $89 \mathrm{had}$ a count greater than $800 \mathrm{cfu} / \mathrm{mL}$ (Cortimiglia et al., 2016).

A total of 1,101 Staph. aureus isolates from 398 positive milk samples were genotyped by RS-PCR. Major RS-PCR genotypes with their variants were combined into CL. Eighty genotypes were found, distributed in 47 CL. A single genotype was detected in 329 samples $(82.6 \%)$, whereas 2 and 3 different genotypes were identified in $55(13.8 \%)$ and 14 samples (3.5\%), respectively. The analyzed isolates were grouped into 8 major CL, in the following order of prevalence: CLB $(\mathrm{n}=141 ; 29.2 \%)$, CLC ( $\mathrm{n}=47 ; 9.8 \%)$, CLR ( $\mathrm{n}=39 ; 8.1 \%)$; CLS ( $\mathrm{n}=31$; $6.5 \%)$; CLI $(\mathrm{n}=29 ; 6.0 \%), \mathrm{CLF}(\mathrm{n}=17 ; 3.5 \%)$, CLBE $(\mathrm{n}=17 ; 3.5 \%)$, and CLZ $(\mathrm{n}=16 ; 3.3 \%)$. The remaining genotypes were distributed in 39 minor CL; they were isolated in fewer than 10 samples. Staphylococcus aureus CLB was particularly prevalent in the provinces of Sondrio, Bergamo, and Brescia, respectively in 63, 38 , and $33 \%$ of the tested BTM samples (Table 1). This prevalence was probably because alpine pasture is a very common practice in these provinces: animals from different herds of origin are usually mixed and share milking equipment, so Staph. aureus contagious strains can easily spread among the animals (Berchtold et al., 2014). Our results confirm that Staph. aureus CLB is very widespread in Lombard herds, as already described for other European countries (Cosandey et al., 2016). Similarly, Staph. aureus CLC, CLR, CLS, CLI, and CLF appeared to be significantly present, whereas CLZ seemed to be more common in Lombardy than in other countries (Cosandey et al., 2016).

Our MLST analysis of the selected 86 Staph. aureus strains showed 26 different sequence types (ST), grouped into 16 clonal complexes (CC). A minimum spanning tree was constructed to depict the frequency and genetic relatedness among the ST detected in this study (Figure 1). In 1 case we could not determine the $\mathrm{CC}$, and the strain had a new ST; in 2 other cases we could only define the CC (CC15 and CC133). We found that $\mathrm{CC} 8$ and $\mathrm{CC} 97$ were the most frequent among MSSA strains ( $\mathrm{n}=22$ and 8 , respectively), whereas

Table 1. Distribution of the main ribosomal spacer PCR (RS-PCR) genotypic clusters (CL) found in different provinces of the Lombardy region: single genotypes isolated from each bulk tank milk sample

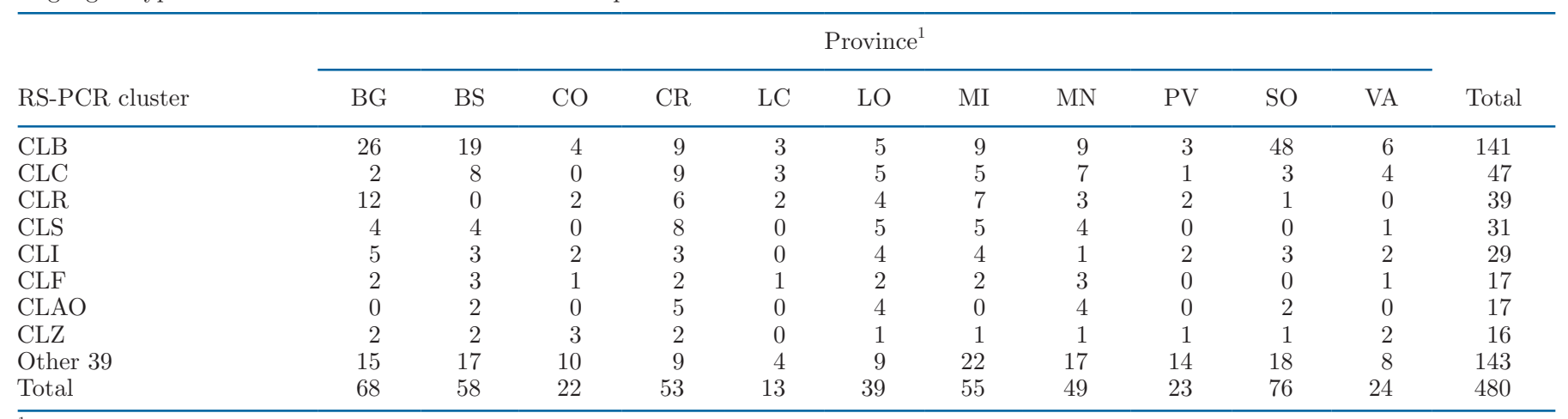

${ }^{1}$ Province: $\mathrm{BG}=$ Bergamo; $\mathrm{BS}=$ Brescia $\mathrm{CO}=\mathrm{Como} ; \mathrm{CR}=$ Cremona; $\mathrm{LC}=$ Lecco; $\mathrm{LO}=$ Lodi; $\mathrm{MI}=\mathrm{Milano} ; \mathrm{MN}=\mathrm{Mantova} ; \mathrm{PV}=\mathrm{Pavia} ;$ $\mathrm{SO}=$ Sondrio $; \mathrm{VA}=$ Varese. 
CC398 ( $\mathrm{n}=14)$, CC1 $(\mathrm{n}=7)$, and CC97 itself ( $\mathrm{n}=$ 7) were prevalent among MRSA strains (Cortimiglia et al., 2016). The MLST analysis of MSSA strains revealed genotypes already found in bovine milk (CC8, CC97, CC151), whereas MRSA strains belonged to livestockassociated lineages (CC398, CC97, and CC1; Boss et al., 2016; Cosandey et al., 2016). Comparison of RSPCR and MLST analysis results showed that 18 Staph. aureus CLB strains belonged to CC8, and 17 were ST8. We found good correspondence between Staph. aureus CLS and ST398 (12 out of 13 strains), whereas the remaining ST398 MRSA belonged to minor clusters (CLCI and CLCF). As reported in Figure 1, a total of 12 strains were ST97, and they were CLAO, CLR, CLBI, and CLN. Every ST1 strain was MRSA, and 4 out of 7 were identified as CLBJ. Concerning the lessfrequent genotypic clusters, we discovered variability about CC and ST, even within the same CL (Table 2).

Our results confirmed a general agreement between RS-PCR and MLST (Cosandey et al., 2016), especially for CLB (CC8) and CLS (CC398), whereas variability occurred among other CL (Figure 1). The MLST analysis showed that genotypes reported as bovine-associated MSSA (CC8, CC97, CC151) and livestock-associated MRSA (CC398, CC97, CC1; Boss et al., 2016; Cosandey et al., 2016) are the most common in Lombardy. We found a great variability of Staph. aureus strains circulating in dairy herds: some analyzed strains had new ST not yet recognized in the MLST database at the time of writing. Moreover, of the 86 Staph. aureus MLST-analyzed strains, 23 carried the adlb gene in their genome, and most belonged to CLB (corresponding to CC8; 17 out of 20, 85\%). Conversely, only 9\% (6 of 66) of non-CLB strains were adlb-positive, and they belonged to several other genotypes: CLS (corresponding to CC398; 2), CLAA (CC5; 1), CLBI (CC97; 2), and CLBJ (CC1; 1) (Table 2). These results confirmed the association between CLB and the adlb gene (Sartori et al., 2017), even though some non-CLB strains carried it too.

The $\mathrm{cfu} / \mathrm{mL}$ count and the SCC for each CL were calculated as mean by SD, as shown in Table 3. In 329 of the 398 positive samples, Staph. aureus isolates belonged to the same genotype (RS-PCR cluster) within each BTM sample, whereas in the remaining 69 samples, 2 or more different genotypes were identified within each sample. For this reason, we considered for statistical analyses only the 329 samples containing a single Staph. aureus genotype (the one circulating in the herd of origin of the sample). Counts of Staph. aureus were not achievable in 3 samples because, although typical colonies were recognized and genotyped, it was impossible to obtain a reliable count of them due to the overgrowth of contaminant environmental bacteria; thus, 326 BTM samples were included in the statistical analyses.

Considering the main CL, observed in at least 10 BTM samples, the relationship between CL and Staph. aureus count or SCC within each sample was evaluated. In this way, 8 CL represented in 232 BTM samples (i.e., herds) were considered: 100 samples were positive for Staph. aureus CLB, 40 for CLC, 21 for CLS, 20 for CLI, 17 for CLR, 13 for CLAO, 11 for CLZ, and 10 for CLF. The 94 remaining samples represented 36 minor CL. The results showed that BTM samples positive for Staph. aureus CLB had a specific cfu/mL count higher than both the samples positive for the 7 most represented non-CLB clusters and the "other CL" group. Compared with CLB, every sample positive for non-CLB clusters revealed a statistically lower $\mathrm{cfu} / \mathrm{mL}$ count (all $P$-values $\leq 0.003$ ), especially CLC, CLS, and "other CL" $(P<0.0001)$. The boxplot representation confirmed that Staph. aureus $\mathrm{cfu} / \mathrm{mL}$ count in BTM was significantly higher in CLB-positive samples than in those positive for other CL (Figure 2).

Because the presence of Staph. aureus in BTM essentially depends on the number of infected lactating cows and on the number of microorganisms eliminated by each infected quarter, our results indirectly confirm the contagious properties of Staph. aureus CLB. This agrees with previous studies (Fournier et al., 2008; Graber et al., 2009; Cremonesi et al., 2015) demonstrating that Staph. aureus CLB is associated with high contagiousness and pathogenicity, and with high prevalence of IMI in the infected herds. On the contrary, Staph. aureus CLC is associated with non-contagious behavior and generally infects single cows within a herd and single quarters of the udder; the same is probably true for the other non-CLB strains. Unlike the Staph. aureus count in BTM, the SCC parameter did not appear to be clearly associated with the presence of CLB or any other particular cluster. Except for CLR and CLZ, where a difference was evidenced $(P<0.05)$, we found no significant differences in SCC between the BTM samples positive for CLB and those positive for other CL (Table 3). The differences found for CLR and CLZ could therefore be random, due to both the low number of observations and the fact that SCC is a nonspecific parameter also influenced by other mammary pathogens not investigated in the present study.

In conclusion, this study provided an overview of Staph. aureus strains circulating in the region of Lombardy in northern Italy, which is a very relevant area for bovine milk production, and underlines the importance of characterizing isolates for their contagious properties. Our results also provide useful elements for further 

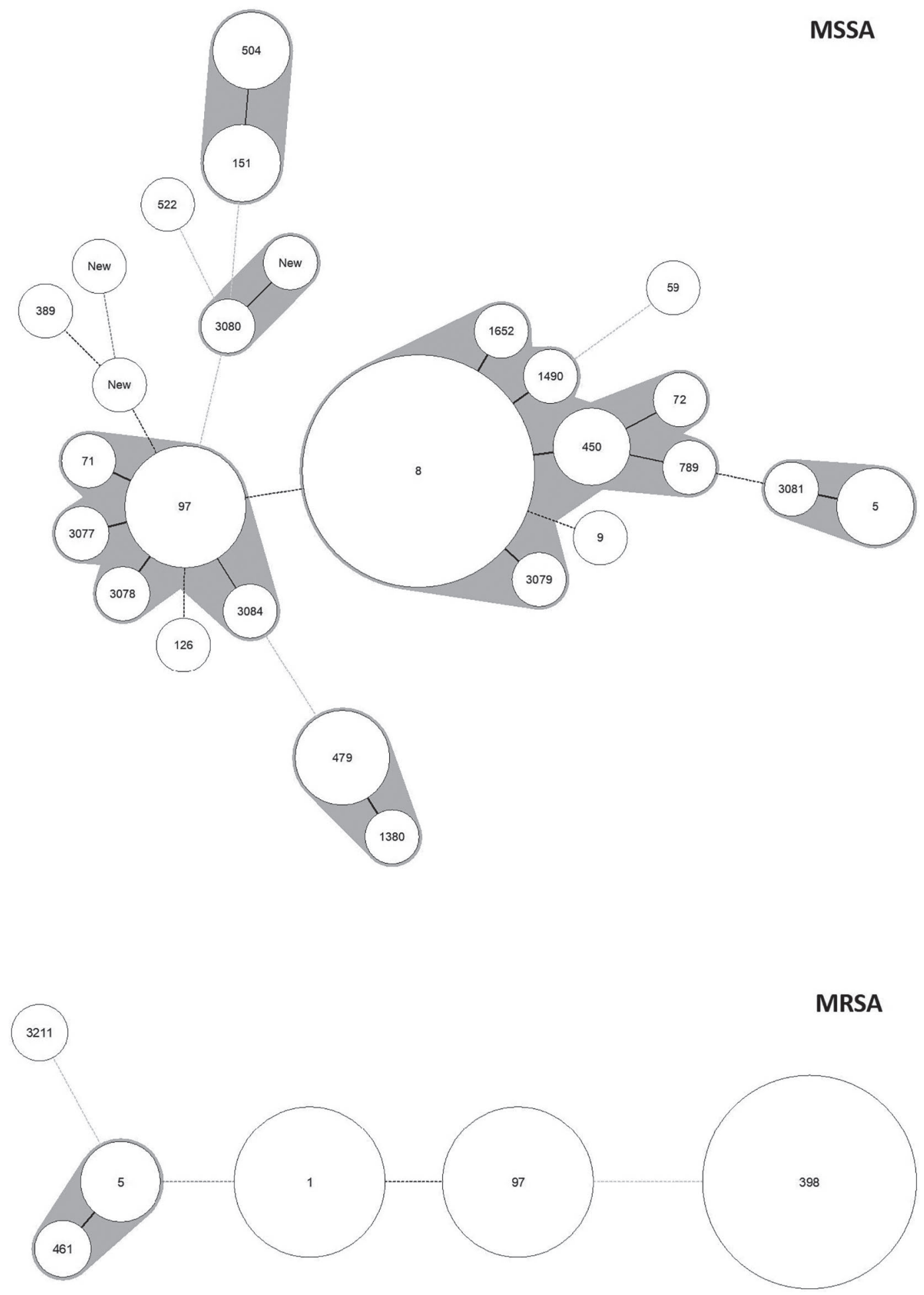

Figure 1. Minimum spanning trees for 86 Staphylococcus aureus strains selected by frequency and geographical origin. Selection consisted of 56 methicillin-sensitive Staph. aureus (MSSA), a subset of MSSA isolates that includes both the more relevant and the rare ribosomal spacerPCR genotypic clusters, considering each province, and 32 methicillin-resistant Staph. aureus (MRSA), composed of all MRSA, each of which was analyzed by Cortimiglia and coworkers (2016) using multi-locus sequence typing (MLST). Analysis was based on MLST results and elaborated with BioNumerics 7.6 (Applied Maths, Sint-Martens-Latem, Belgium). 
Table 2. Ribosomal spacer PCR (RS-PCR) genotypic clusters (CL), multi-locus sequence typing (MLST) analysis, and adlb-positive (adlb+) strains of the group of 86 Staphylococcus aureus selected by frequency and geographical origin

\begin{tabular}{|c|c|c|c|c|}
\hline Status & Cluster & No. & MLST (no.) & No. $a d l b+$ \\
\hline \multirow{11}{*}{ MSSA } & CLS & 1 & CC352-ST3084 (1) & 0 \\
\hline & CLR & 3 & CC97-ST97 (1); CC97-ST3078 (1); CC133-ND (1) & 0 \\
\hline & CLAF & 2 & CC8-ST450 (1); CC5-ST3081 (1) & 0 \\
\hline & CLF & 3 & CC97-ST9 (1); CC7-ST789 (1); ND-new (1) & 0 \\
\hline & CLAD & 2 & CC72-ST72 (1); CC126-ST126 (1) & 0 \\
\hline & CLBI & 2 & CC97-ST97 (2) & 2 \\
\hline & CLI & 2 & CC352-ST71 (1); CC15-ND (1) & 0 \\
\hline & CLN & 2 & CC59-ST59 (1); CC97-ST97 (1) & 0 \\
\hline & CLP & 2 & CC479-ST479 (2) & 0 \\
\hline & CLZ & 2 & CC479-ST479 (1); CC479-ST1380 (1) & 0 \\
\hline & Other CL & 3 & CC8-ST8 (1); CC133-ST3080 (1); CC389-ST389 (1) & 0 \\
\hline \multirow{6}{*}{ MRSA } & CLBJ & 4 & CC1-ST1 (4) & 1 \\
\hline & CLAF & 2 & CC5-ST5 (1); CC5-ST461 (1) & 0 \\
\hline & CLK & 1 & CC5-ST5 (1) & 0 \\
\hline & CLA & 2 & CC1-ST1 (2) & 0 \\
\hline & Other CL & 2 & CC398-ST398 (2) & 0 \\
\hline & Total & 32 & - & 3 \\
\hline
\end{tabular}

${ }^{1}$ Selection consisted of 56 methicillin-sensitive Staph. aureus (MSSA) strains (a subset of MSSA isolates including both the more relevant and the rare RS-PCR genotypic clusters, considering each province) and 32 methicillin-resistant Staph. aureus (MRSA) strains. This second group is composed of all the MRSA, each of which was analyzed by Cortimiglia and coworkers (2016) using MLST.

epidemiological studies on Staph. aureus, which may be conducted in different Italian areas or in other countries. Staphylococcus aureus CLB strains are strongly adapted to cattle and clearly contagious; they can produce toxins and are very common in Italian dairy herds, as well as in other European countries. Therefore, mammary infection caused by CLB represents a serious risk for dairy productions. Furthermore, in the dairy cattle population in Lombardy, and probably in other Italian regions and other countries too, great variability of Staph. aureus strains was demonstrated in bovine IMI, and contagiousness is not exclusively associated with CLB. In this view, more specific markers should be investigated, and the $a d l b$ gene proved to be a good candidate. If the association of the $a d l b$ gene with the contagiousness of the isolates is completely ascertained, analysis of this unique target may be easily and routinely carried out to detect particularly contagious strains and thus to direct more severe control interventions by farmers and practitioners.

Table 3. Difference in Staphylococcus aureus count and SCC in bulk tank milk (BTM) samples sharing Staph. aureus of different genotypic clusters (CL) compared with cluster B

\begin{tabular}{|c|c|c|c|c|c|c|c|}
\hline \multicolumn{2}{|c|}{ Staph. aureus in BTM } & \multicolumn{3}{|c|}{ Staph. aureus $\left(\mathrm{cfu} / \mathrm{mL} \times 10^{2}\right)$} & \multicolumn{3}{|c|}{$\mathrm{SCC} / \mathrm{mL} \times 1,000$} \\
\hline CLB (reference) & 100 & 5.8 & {$[4.0-8.3]$} & - & 343 & {$[288-408]$} & - \\
\hline CLS & 21 & 0.6 & {$[0.3-1.3]$} & $<0.0001$ & 473 & {$[323-691]$} & 0.13 \\
\hline CLI & 20 & 1.5 & {$[0.6-3.3]$} & 0.002 & 303 & {$[205-447]$} & 0.57 \\
\hline CLR & 17 & 1.4 & {$[0.6-3.3]$} & 0.003 & 561 & {$[368-856]$} & 0.035 \\
\hline CLF & 10 & 0.7 & {$[0.2-1.9]$} & 0.0002 & 365 & {$[210-633]$} & 0.83 \\
\hline Other CL & 94 & 1.2 & {$[0.8-1.8]$} & $<0.0001$ & 388 & [324-464] & 0.34 \\
\hline
\end{tabular}




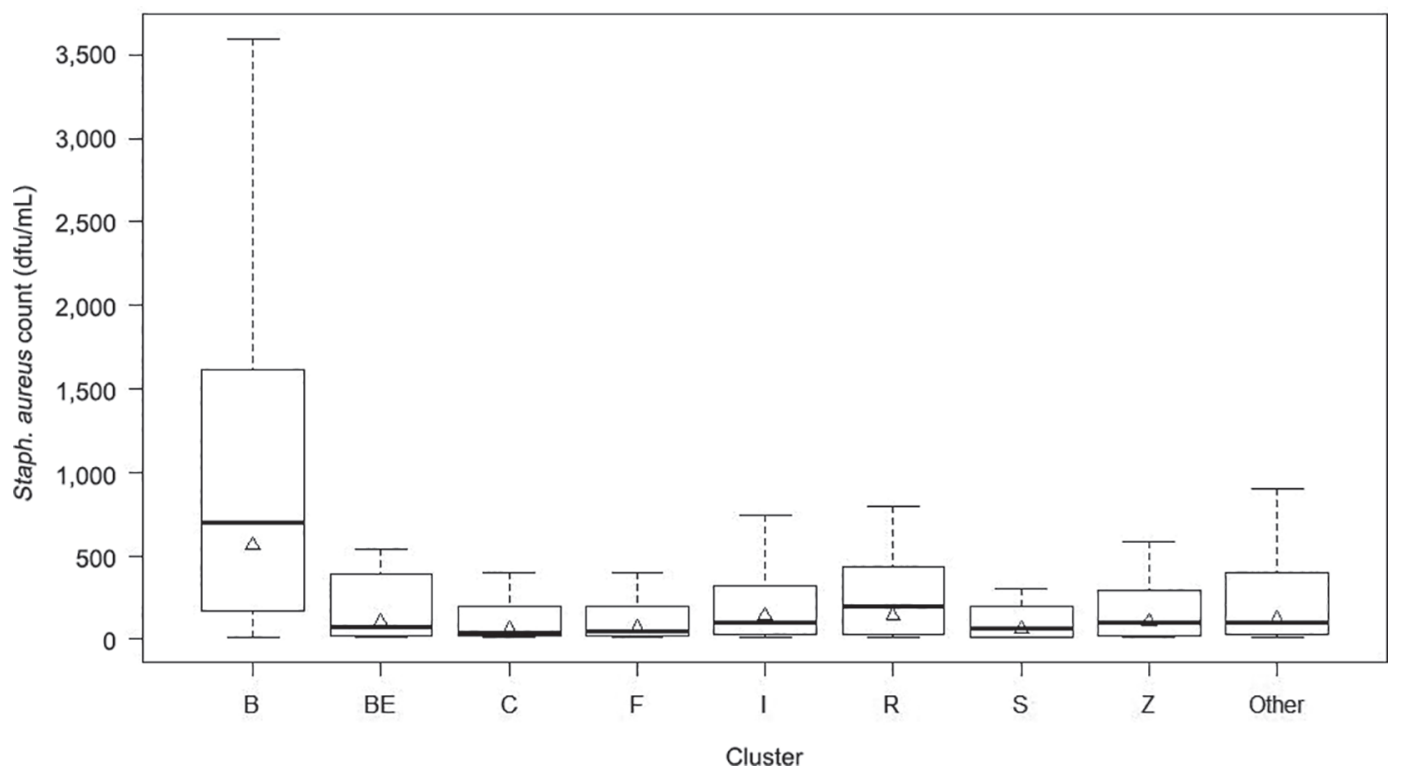

Figure 2. Boxplot representation of Staphylococcus aureus $\mathrm{cfu} / \mathrm{mL}$ count in bulk tank milk samples, by genotypic cluster of the isolates obtained from the same sample. The box indicates quartiles of distribution (Q1, median, and Q3), whiskers and relative lines indicate minimum $(\mathrm{Q} 1-1.5 \times$ interquartile range) and maximum $(\mathrm{Q} 3+1.5 \times$ interquartile range $)$ of data distribution, and triangles are log-mean count of each cluster.

\section{ACKNOWLEDGMENTS}

The authors thank Francesca Pozzi, Antonia Riboni, and Lorenza Sala (Istituto Zooprofilattico della Lombardia e dell'Emilia Romagna, Lody, Italy) for the valuable technical assistance in bacteriological and PCR analysis, and Antonio Parisi (Istituto Zooprofilattico di Puglia e Basilicata, Foggia, Italy) for the minimum spanning tree analysis. This work was funded by the Italian Ministry of Health (Rome), Research Project IZSLER 2014/11 "Epidemiology of Staphylococcus aureus methicillin-resistant (MRSA) and Staphylococcus aureus methicillin-susceptible (MSSA) in dairy herds and dairy products." The authors declare no conflicts of interest.

\section{REFERENCES}

Ali, A., and G. Shook. 1980. An optimum transformation for somatic cell concentration in milk. J. Dairy Sci. 63:487-490. https://doi .org/10.3168/jds.S0022-0302(80)82959-6.

Berchtold, B., M. Bodmer, B. H. P. Van Den Borne, M. Reist, H. U. Graber, A. Steiner, R. Boss, and F. Wohlfender. 2014. Genotypespecific risk factors for Staphylococcus aureus in Swiss dairy herds with an elevated yield-corrected herd somatic cell count. J. Dairy Sci. 97:4886-4896. https://doi.org/10.3168/jds.2013-7760.

Boss, R., A. Cosandey, M. Luini, K. Artursson, M. Bardiau, F. Breitenwieser, E. Hehenberger, T. Lam, M. Mansfeld, A. Michel, G. Mösslacher, J. Naskova, S. Nelson, O. Podpečan, A. Raemy, E. Ryan, O. Salat, P. Zangerl, A. Steiner, and H. U. Graber. 2016. Bovine Staphylococcus aureus: Subtyping, evolution, and zoonotic transfer. J. Dairy Sci. 99:515-528. https://doi.org/10.3168/jds .2015-9589.
Cortimiglia, C., M. Luini, V. Bianchini, L. Marzagalli, F. Vezzoli, D. Avisani, M. Bertoletti, A. Ianzano, A. Franco, and A. Battisti. 2016. Prevalence of Staphylococcus aureus and of methicillin-resistant $S$. aureus clonal complexes in bulk tank milk from dairy cattle herds in Lombardy Region (Northern Italy). Epidemiol. Infect. 144:3046-3051. https://doi.org/10.1017/S0950268816001576.

Cosandey, A., R. Boss, M. Luini, K. Artursson, M. Bardiau, F. Breitenwieser, E. Hehenberger, T. H. Lam, M. Mansfeld, A. Michel, G. Mösslacher, J. Naskova, S. Nelson, O. Podpečan, A. Raemy, E. Ryan, O. Salat, P. Zangerl, A. Steiner, and H. U. Graber. 2016. Staphylococcus aureus genotype B and other genotypes isolated from cow milk in European countries. J. Dairy Sci. 99:529-540. https://doi.org/10.3168/jds.2015-9587.

Cremonesi, P., F. Pozzi, M. Raschetti, G. Bignoli, E. Capra, H. U. Graber, F. Vezzoli, R. Piccinini, B. Bertasi, S. Biffani, B. Castiglioni, and M. Luini. 2015. Genomic characteristics of Staphylococcus aureus strains associated with high within-herd prevalence of intramammary infections in dairy cows. J. Dairy Sci. 98:68286838. https://doi.org/10.3168/jds.2014-9074.

Enright, M. C., N. P. Day, C. E. Davies, S. J. Peacock, and B. G. Spratt. 2000. Multilocus sequence typing for characterization of methicillin-resistant and methicillin-susceptible clones of Staphylococcus aureus. J. Clin. Microbiol. 38:1008-1015.

Fetrow, J., K. Anderson, S. Sexton, and K. Butcher. 1988. Herd composite somatic cell counts: Average linear score and weighted average somatic cell count score and milk production. J. Dairy Sci. 71:257-260. https://doi.org/10.3168/jds.S0022-0302(88)79550-8.

Filipello, V., M. Tilola, L. Zani, B. Bertasi, M. Luini, and G. Finazzi. 2019. Characterization of Staphylococcus aureus isolates from traditional dairy products of small-scale alpine farms. Ital. J. Food Sci. 31:67-74. https://doi.org/10.14674/IJFS-1179.

Fournier, C., P. Kuhnert, J. Frey, R. Miserez, M. Kirchhofer, T. Kaufmann, A. Steiner, and H. U. Graber. 2008. Bovine Staphylococcus aureus: Association of virulence genes, genotypes and clinical outcome. Res. Vet. Sci. 85:439-448. https://doi.org/10.1016/j .rvsc.2008.01.010.

Graber, H. U., J. Naskova, E. Studer, T. Kaufmann, M. Kirchhofer, M. Brechbühl, W. Schaeren, A. Steiner, and C. Fournier. 2009. Mastitis-related subtypes of bovine Staphylococcus aureus are charac- 
terized by different clinical properties. J. Dairy Sci. 92:1442-1451. https://doi.org/10.3168/jds.2008-1430.

Hogeveen, H., O. Huijps, and T. J. G. M. Lam. 2011. Economic aspects of mastitis: New developments. N. Z. Vet. J. 59:16-23. https: //doi.org/10.1080/00480169.2011.547165.

Hummerjohann, J., J. Naskova, A. Baumgartner, and H. U. Graber. 2014. Enterotoxin-producing Staphylococcus aureus genotype B as a major contaminant in Swiss raw milk cheese. J. Dairy Sci. 97:1305-1312. https://doi.org/10.3168/jds.2013-7643.

Johler, S., D. Weder, C. Bridy, M. C. Huguenin, L. Robert, J. Hummerjohann, and R. Stephan. 2015. Outbreak of staphylococcal food poisoning among children and staff at a Swiss boarding school due to soft cheese made from raw milk. J. Dairy Sci. 98:2944-2948. https://doi.org/10.3168/jds.2014-9123.

Kümmel, J., B. Stessl, M. Gonano, G. Walcher, O. Bereuter, M. Fricker, T. Grunert, M. Wagner, and M. Ehling-Schulz. 2016. Staphylococcus aureus entrance into the dairy chain: Tracking $S$. aureus from dairy cow to cheese. Front. Microbiol. 7:1603. https://doi .org/10.3389/fmicb.2016.01603.

Luini, M., P. Cremonesi, G. Magro, V. Bianchini, G. Minozzi, B. Castiglioni, and R. Piccinini. 2015. Methicillin-resistant Staphylococcus aureus (MRSA) is associated with low within-herd prevalence of intra-mammary infections in dairy cows: Genotyping of isolates. Vet. Microbiol. 178:270-274. https://doi.org/10.1016/j.vetmic 2015.05.010.
Petzer, I. M., J. Karzis, E. F. Donkin, E. C. Webb, and E. M. C. Etter. 2017. Validity of somatic cell count as indicator of pathogenspecific intramammary infections. J. S. Afr. Vet. Assoc. 88:a1465. https://doi.org/10.4102/jsava.v88i0.1465.

Sartori, C., R. Boss, I. Ivanovic, and H. U. Graber. 2017. Development of a new real-time quantitative PCR assay for the detection of Staphylococcus aureus genotype B in cow milk, targeting the new gene adlb. J. Dairy Sci. 100:7834-7845. https://doi.org/10.3168/ jds.2017-12820.

Syring, C., R. Boss, M. Reist, M. Bodmer, J. Hummerjohann, P. Gehrig, and H. U. Graber. 2012. Bovine mastitis: The diagnostic properties of a PCR-based assay to monitor the Staphylococcus aureus genotype B status of a herd, using bulk tank milk. J. Dairy Sci. 95:3674-3682. https://doi.org/10.3168/jds.2011-4968.

\section{ORCIDS}

A. Gazzola $\odot$ https://orcid.org/0000-0003-0322-4061

H. U. Graber () https://orcid.org/0000-0002-4065-0548

P. Cremonesi ㅇ https://orcid.org/0000-0002-8239-5549

M. Luini $\odot$ https://orcid.org/0000-0003-4508-997X 